\title{
RETRACTED ARTICLE: Identification of the Interaction Between the Human Homologue of the Arabidopsis COP9 Signalosome Subunit 7a and Olig1
}

\author{
Jiazhen $\mathrm{Zhou}^{1} \cdot$ Yuanyuan $\mathrm{Li}^{1} \cdot$ Cheng $\mathrm{He}^{1}$
}

Received: 15 June 2015/Accepted: 19 August 2015/Published online: 26 August 2015

(C) Springer Science+Business Media New York 2015

This article has been retracted by the Editor-in-Chief due to unethical conduct on part of the authors. The authors admitted they falsified authorship and submitted the article under false pretenses. This retraction is at the request of Dr. Cheng He who is not an author of this paper and does not support the content presented.
Electronic supplementary material The online version of this article (doi:10.1007/s10571-015-0255-x) contains supplementary material, which is available to authorized users.

\section{Cheng $\mathrm{He}$}

hmhcsmmu@163.com

1 Institute of Neuroscience and MOE Key Laboratory of Molecular Neurobiology, Second Military Medical

University, Shanghai 200433, China 